
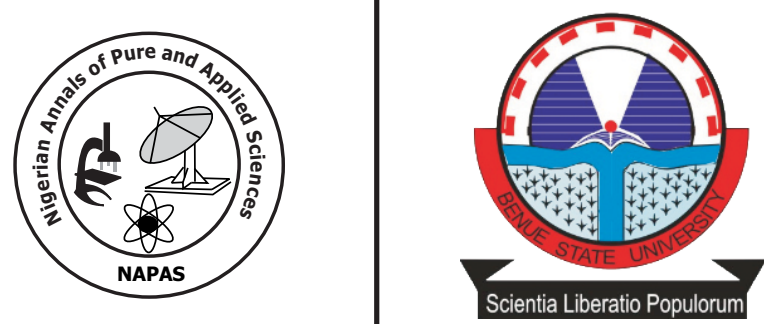

\title{
Abbatoir Survey of Intestinal Parasites among Sheep in Katsina State, Nigeria
}

\author{
${ }^{1}{ }^{1}$ Agba, A. A., ${ }^{1}$ Aguh, I. B. and ${ }^{2}$ Uweh Philomena Odeh \\ ${ }^{1}$ Department of Biological Sciences, Federal University Gusau, Nigeria. \\ ${ }^{2}$ Biology Department, College of Advance and Professional Studies, \\ Makurdi, Nigeria \\ *Corresponding Author:fredagba14@gmail.com
}

\begin{abstract}
Faecal samples collected from seven hundred sheep brought for slaughter in some abattoirs in six Local Government Areas of Katsina State were examined for presence of intestinal parasites. The samples were examined for eggs of parasites using direct smear and formol-ether concentration technique. The overall prevalence was 236(33.7\%). The cestode identified was Moniezia sp. 16(2.3\%). The coccidian oocyts had a prevalence of 8.6\%. The nematodes identified were Strongyle sp. 116(16.6\%) and Trichuris sp. 17(2.4\%), while the only trematode identified was Fasciola sp. 17(2.4\%). Factors such as sex, age and breed of the sheep were found not to significantly influence the prevalence of infection $(P>0.05)$. The results of the study showed that season was a factor which can significantly influenced the prevalence of infection among sheep in the study area $(\mathrm{P}<0.05)$. The study identified high prevalence of intestinal parasites among sheep slaughtered in the six abattoirs. Therefore, strategic control approach by using effective broad spectrum chemotherapeutics especially at the beginning of rainy season to reduce the burden of infection is recommended.
\end{abstract}

Key words: Sheep, Cestodes, Coccidian oocyts, Nematodes, Trematodes. 


\section{Introduction}

Nigeria has an estimated 22.1 million sheep of various breeds found predominantly in the northern region due to the favourable microclimatic conditions (Bourn et al., 2018). In Nigeria, sheep are not only kept for meat and skin but also for religious and social ceremonies as well as a source of income (Lawal-Adebowale, 2012; Adua et al., 2017).

Gastro intestinal parasites which include various helminthes and protozoan parasites are world-wide problem to some animals in tropical and subtropical countries but their impact is greater in Sub-Saharan Africa due to the availability of a wide range of agro-ecological factors suitable for diversified hosts and parasite species (Regassa et al., 2006; Murthy and Rao, 2014; Karaye et al., 2018 ). These parasites causes considerable global economic losses as a consequence of reduced weight gain, digestive disturbance, lowered production, impaired reproductive performance, condemnation of affected organs, and mortality of infected animals (Raza et al., 2007).

In sheep, the wool quality and yield is reduced due to deficiency in essential amino acids which is required for the growth of the wool and grease fleece (Murthy and Rao, 2014). Although several studies have been carried out with respect to diversity and prevalence of gastrointestinal parasites in animals in different parts of Nigeria (Jatau et al., 2011; Jegede et al., 2015; Paul et al., 2016; Karaye et al., 2018). To the best of our knowledge, only one study has been carried out in Katsina State on sheep. Okaiyeto et al. (2008) in their survey of gastrointestinal parasites of nomadic sheep in eight Local Government Areas of Northern Nigeria, were able to survey only one Local Government Area within Katsina State. This present study is necessary to give a proper and more detail understanding of the diversity, prevalence, distribution and risk factors associated with infection within the state for rational design of effective preventive and control measures against the infections.

\section{Materials and Methods Study Area}

The study was carried out in six Local Governments Areas within Katsina State. Katsina State covers an area of 24,192 sq km and is located between latitudes $12^{\circ} 15^{\prime} \mathrm{N} ; 12^{\circ} 50^{\prime} \mathrm{N}$ and longitudes $7^{\circ} 30^{\prime} \mathrm{E} ; 7^{\circ} 58^{\prime} \mathrm{E}$. The state is bounded to the north by Niger Republic, to the east by Jigawa and Kano States, to the west by Zamfara State and to the south by Kaduna State. Water supply is sourced through the damming of rivers, reservoirs and digging of wells and boreholes because most of the rivers, streams, lakes and reservoirs dry out during the dry season. The state has a varying climate with a cool dry season (harmattan) from October to February, hot dry season from March to May and a warm wet season from June to September.

\section{Study design}

Two Local Government Areas were selected from each of the three vegetation zones giving a total of six Local Governments. 700 faecal samples were collected and examined for presence of intestinal parasites. The study was carried out from November 2017 to October 2018 to cover both the dry and rainy seasons.

Table 1: List of Vegetation Zones and Local Government Abattoirs sampled

\begin{tabular}{|c|c|c|c|}
\hline Vegetation Zones & $\begin{array}{l}\text { Characteristics of each } \\
\text { Vegetation Zone }\end{array}$ & $\begin{array}{l}\text { Local Government Areas } \\
\text { Sampled }\end{array}$ & $\begin{array}{l}\text { Coordinates of Sampled } \\
\text { Local Government Area }\end{array}$ \\
\hline Zone A & $\begin{array}{l}\text { Southern part of } \mathrm{t} \text { he state; } \\
\text { vegetation similar to that of the } \\
\text { Northern Guinea Savanna; mean } \\
\text { annual rainfall about } 1000 \mathrm{~mm}\end{array}$ & Funtua & $\begin{array}{l}11^{\circ} 32^{\prime} \mathrm{N} ; 7^{\circ} 19 \text { " E and } \\
11.33^{\circ} \mathrm{N} ; 7.317^{\circ} \mathrm{E}\end{array}$ \\
\hline \multirow[t]{2}{*}{ Zone B } & $\begin{array}{l}\text { Centre of the state; vegetation } \\
\text { similar to that of Sudan Savanna; } \\
\text { mean annual rainfall about }\end{array}$ & Kankara & $\begin{array}{l}11^{\circ} 55^{\prime} \mathrm{N} ; 7^{\circ} 24^{\prime} \mathrm{E} \text { and } \\
52.10^{\prime \prime} \mathrm{N} ; 40.14^{\prime \prime} \mathrm{E}\end{array}$ \\
\hline & $500 \mathrm{~mm}$ & Dutsin-Ma & $\begin{array}{l}12^{\circ} 27^{\prime} 18^{\prime \prime} \mathrm{N} ; 7^{\circ} 29^{\prime} 29 \quad " \mathrm{E} \\
\text { and } 12.45500^{\circ} \mathrm{N} ; \\
7.49139^{\circ} \mathrm{E}\end{array}$ \\
\hline
\end{tabular}


Zone C

northern part of the state; vegetation similar to that of Sahel Savanna; mean annual rainfall that is less than $300 \mathrm{~mm}$
Baure

$12^{\circ} 47^{\prime} \mathrm{N} ; 8^{\circ} 46^{\prime} \mathrm{E}$ and

$12.783^{\circ} \mathrm{N} ; 8.767^{\circ} \mathrm{E}$

Maiadua

\author{
$13^{\circ} 11^{\prime} 26^{\prime \prime} \mathrm{N} ; 8^{\circ} 12^{\prime} 42$ " E \\ and $13.19056^{\circ} \mathrm{N}$ \\ $8.21167^{\circ} \mathrm{E}$
}

\section{Ethical consideration}

Permission was obtained from the Director, Veterinary Services under the Ministry of Agriculture and Natural Resources, Katsina State as well as the managers of the abattoirs before faecal samples were collected.

\section{Faecal sample collection}

The samples were collected directly from the rectum of the animals immediately after they were slaughtered using disposable hand gloves and transferred into sterile, labelled, wide mouthed specimen bottles with screw caps, preserved in $10 \%$ formalin solution and taken to the Parasitology Laboratory, Department of Zoology, Ahmadu Bello University, Zaria for microscopic examination.

\section{Collection of Data}

A structured questionnaire was used to obtain information on sex which was by examination of the genitalia. The age of the sheep was determined by using the guide of FAO (1994) While the breed of the sampled sheep was determined using the guide of Lawal-Adebowale, (2012).

\section{Faecal Sample processing}

The modified Formol-Ether concentration technique was be used to concentrate eggs and cysts of the gastrointestinal parasites (Cheesbrough, 2009). Briefly, $1 \mathrm{~g}$ of stool sample was emulsified with $4 \mathrm{ml}$ of $10 \%$ formol saline in a test tube. The mixture was filtered into a test tube using a cloth gauge and 3-4 $\mathrm{ml}$ of diethyl ether was added and shaken vigorously and allowed to stand for two minutes. The mixture was then centrifuged at 1000 revolutions per minutes (1000 rpm) for 3 minutes. Using a glass rod, the faecal debris from the side of the tube was loosened and the tube inverted to pour off the supernatants. The tube was returned to its original upright position and the fluid from the side of the tube allowed draining to the bottom. The bottom of the tube was tapped to resuspend and mix the sediment. The sediment was transferred to a slide, stained with Lugols Iodine and examined for presence of eggs of parasites using the X10 and X40 objectives respectively. Parasite identification was done using the keys of (Kaufmann, 1996; Foreyt, 2001).

\section{Data analysis}

Percentages were using in determining the prevalence of infection. The relationship between the prevalence of infection to the sex, age breed, season and vegetation zones were determined using chi square $\left(\chi^{2}\right)$. $P$-value of $<0.05$ was considered as statistically significant. All data analysis was done using the Statistical Package for Social Sciences (SPSS) Version 21.0.

\section{RESULTS}

The results of the study revealed that $236(33.7 \%)$ of the 700 sheep examined were infected with intestinal parasites. The cestode identified was Moniezia sp. 16(2.3\%). The coccidian oocyts had a prevalence of $8.6 \%$. The nematodes identified were Strongyle sp. 116(16.6\%) and Trichuris sp. 17(2.4\%), while the only trematode identified was Fasciola sp. 17(2.4\%). (Table 2). Findings from this study also showed that Prevalence of infection was higher in Funtua and Kafur Local Government Areas which represented zone A compared to other Local Government Areas in zones $\mathrm{B}$ and $\mathrm{C}$ respectively $(\mathrm{P}>0.05)$. Male sheep had more prevalence $(38.5 \%)$ than the female $(31.3 \%)$ (Table 4$)$. 
Table 2: Frequency of intestinal parasites among 700 sheep examined

\begin{tabular}{lll}
\hline Parasite species & Number infected & Prevalence (\%) \\
\hline Moniezia sp. & 16 & 2.3 \\
Coccidian oocyts & 70 & 8.6 \\
Strongyle sp. & 116 & 16.6 \\
Trichuris sp. & 17 & 2.4 \\
Fasciola sp. & 17 & 2.4 \\
Total & 236 & 33.7 \\
\hline
\end{tabular}

Table: 3 Prevalence of gastrointestinal infection in relation to Local Government Areas sampled

\begin{tabular}{llll}
\hline $\begin{array}{l}\text { Local Govt. Area } \\
\text { sampled }\end{array}$ & Number Examined & Number Infected & Prevalence (\%) \\
\hline Funtua & 126 & 46 & 36.5 \\
Kafur & 114 & 43 & 37.7 \\
Kankara & 105 & 33 & 31.4 \\
Dutsin-Ma & 119 & 37 & 31.1 \\
Baure & 115 & 38 & 33.0 \\
Maidua & 121 & 39 & 32.2 \\
Total & 700 & 236 & 33.7 \\
\hline
\end{tabular}

Table 4: Prevalence of intestinal parasites in relation to sex

\begin{tabular}{llll}
\hline Sex & $\begin{array}{l}\text { Number } \\
\text { Examined }\end{array}$ & Number infected & Prevalence (\%) \\
\hline Male & 231 & 89 & 38.5 \\
Female & 469 & 147 & 31.3 \\
Total & 700 & 236 & 33.7 \\
\hline
\end{tabular}

Sheep between the ages of 4 years and above had the highest prevalence (37.3\%) compared to the $2-3$ years $(32.3 \%)$ as well as the $0-1$ year $(31.1 \%)$ $(P>0.05)$ (Table 5).

Prevalence in relation to the breed of the sheep showed that the Yankassa breed was more infected (36.3\%) compared to the Balami (32.8\%) and Uda (31.3\%) $(P>0.05)$ (Table 6). The findings of this study also showed that season is a factor which significantly influenced the prevalence of infection $(P<0.05)($ Table 7$)$.

Table 5: Prevalence of intestinal parasites in relation to age

\begin{tabular}{llll}
\hline Age & $\begin{array}{l}\text { Number } \\
\text { Examined }\end{array}$ & Number infected & Prevalence (\%) \\
\hline $0-1$ & 151 & 47 & 31.1 \\
$2-3$ & 313 & 101 & 32.3 \\
4 and above & 236 & 88 & 37.3 \\
Total & 700 & 236 & 33.7 \\
\hline
\end{tabular}

Table 6: Prevalence of intestinal parasites in relation to breed

\begin{tabular}{llll}
\hline Breed & $\begin{array}{l}\text { Number } \\
\text { Examined }\end{array}$ & Number infected & Prevalence (\%) \\
\hline Balami & 189 & 62 & 32.8 \\
Uda & 233 & 73 & 31.3 \\
Yankassa & 278 & 101 & 36.3 \\
Total & 700 & 236 & 33.7 \\
\hline
\end{tabular}


Table 7: Prevalence of intestinal parasites in relation to season

\begin{tabular}{llll}
\hline Season & $\begin{array}{l}\text { Number } \\
\text { Examined }\end{array}$ & Number infected & Prevalence (\%) \\
\hline Wet & 350 & 161 & 46.0 \\
Dry & 350 & 75 & 21.4 \\
Total & 700 & 236 & 33.7 \\
\hline
\end{tabular}

\section{Discussion}

The results of this study showed a prevalence of $33.7 \%$ which is higher than the $10.2 \%$ previously reported by Karaye et al. (2018). The prevalence observed prevalence is lower than those obtained by Dawet et al. (2014), Abdullahi et al. (2015) and Ngele et al. (2018). This difference in prevalence may be attributed to the high moisture content and temperature in these locations which favour the growth and development of larvae on pasture resulting to increased interactions between the host and parasites

The higher prevalence obtained among female sheep concurs with the findings of Dawet $e t$ al. (2014). However, Abdullahi et al. (2015) and Jegede et al. (2015) reported a higher prevalence among the male sheep. However, the difference obtained was not statistically significant.

The highest prevalence obtained among the 4 years and above age group is in agreement with the findings of Anene et al. (1994) and Jegede et al. (2015) This high prevalence is not surprising because Previous studies in Nigeria by Nwoke et al. (2015); Ola-Fadunsin and Ibitoye (2017) and Mandado et al. (2016) in Ethiopia have shown that adult sheep were more prone to parasitic diseases than the young one due to the roaming nature of the adults This however contradicts the reports of previous researchers such as Sangma et al. (2012), Raza et al. (2014) and Islam et al. (2017) who reported a higher prevalence among sheep below the age of four.

The findings of this study revealed that the Yankassa breed of cattle were more infected compared to the Balami and Uda which had the least prevalence of infection. This however disagree with the findings of Jegede et al. (2015) who reported the highest prevalence among the Uda breed compared to the Yankassa and Balami breeds. The nonsignificant difference obtained among the different breeds of sheep might be attributed to their exposure to equal sources of infection such as pasture and water.

The results of the study also revealed a significant difference between infection and season of the study. The higher prevalence of infection during wet season is in agreement with the findings of Ola-Fadunsin and Ibitoye (2017) and might be due to high moisture content and moderate temperature which is seen during the wet seasons that favour the growth and development of gastrointestinal parasites and their vectors or infective stages.

\section{Conclusion}

The finding of this study shows that gastrointestinal infection is widespread among sheep slaughtered in some abattoirs within Katsina State. The high infection rates recorded during the wet season is as a result of favourable conditions for the growth and development of the parasites and their infective stages. This may have a negative implication on the productivity of the sheep as well as the risk of zoonotic transmission. Therefore, improving farm management system and routine deworming of these sheep is recommended.

\section{References}

Abdullahi, A.Y., Bringa, A.M. and Gwarzo, Y.S. (2015). A Survey of gastrointestinal helminth parasites of slaughtered sheep around Kano Metropolis. Journal of Biology and Genetic Research, 1(8): 9-16.

Adua, M.M. and Hassan, D.I. (2016). Prevalence of nematode infestation in goats reared in Nasarawa State, Nigeria. Nigerian Journal of Agriculture, Food and Environment, 12(3):79-84

Anene, B.M., Onyekwodiri, E.O., Chime, A.B. and Anika, S.M. (1994). Gastrointestinal parasites of sheep and goats of Southeastern Nigeria. Small Ruminant Research, 13:187-192.

Bourn, D., Wint, W., Blench, R. and Woolley, E. (2018). Nigerian Livestock Resources Survey. Animal Genetic Resources (AnGR) project in Nigeria. Retrieved on $14^{\text {th }}$ May, 2020 from http://angr.org.ng/2018/03/28/nigerianlivestock-resources-survey/

Cheesbrough, M. (2009). District Laboratory Practice in Tropical Countries, Cambridge University Press, New York. 192-200. 
Dawet, A., Yakubu, D. P. and Haledu, U. I. (2014).Gastrointestinal helminths of selected ruminants in Jos, Plateau State, Nigeria. African Journal of Natural Sciences 7:29-36.

Food and Agriculture Organization (FAO). (1994). A manual for the primary health care worker. Retrieved on 23 $3^{\text {rd }}$ January, 2017 from www.fao.org/t0690e00.htm\#contents.

Foreyt, J.W. (2001): Veterinary Parasitology: Reference Manual. Blackwell Publishers. Iowa. Pp: 69-72.

Islam, M.S., Hossain, M.S., Dey, A.R., Alim, M.A., Akter, S. and Alam, M.Z. (2017). Epidemiology of gastrointestinal parasites of small ruminants in Mymensingh, Bangladesh. Journal of Advanced Veterinary and Animal Research, 4(4):356-362.

Jatau, I.D, Abdulganiyu, A, Lawal.A.I, Okubanjo, A.I and Yusu, K.H (2011): Gastrointestinal and haemoparasitism of sheep and goats at slaughter in Kano, northern-Nigeria. Sokoto Journal of Veterinary Sciences, 9(1):7-11.

Jegede, O.C., Adejoh, A.A., Obeta, S.S. and Olayemi, O.D. (2015). Gastrointestinal parasites of sheep and goats in Gwagwalada Area Council, Federal Capital Territory, Abuja, Nigeria; with a special reference to sex, breed and age. Alexandria Journal of Veterinary Sciences, 46:170-176.

Karaye, P. G., Ola-Fadunsin, S. D. and Dogo, G. A. (2018). Diversity of gastrointestinal parasites affecting some domestic animals in Plateau State, North Central Nigeria. Science World Journal, 13(1): 82-86.

Kaufmann, Johannes: (1996). Parasitic infections of domestic animals: a diagnostic manual. Springer, Basel. Pp146-152.

Lawal-Adebowale, O.A. (2012). Dynamics of ruminant livestock management in the context of the Nigerian Agricultural System. In: Livestock Production. InTech. USA. Pp 6163. http://dx.doi.org/10.5772/52923

Mandado T., Argaw, S. and Garedew, L. (2016). The Prevalence of mange infestations in small ruminants in three agro-ecological zones of Wolaita zone, southern Ethiopia. Advances in Life Science and Technology, 42(1): 18-24.

Murthy, G.S.S. and Rao, P.V. (2014). Prevalence of gastro intestinal parasites in ruminants and poultry in Telangana region of Andhra Pradesh. Journal of Parasitic Disease, 38(2):190-192.

Nwoke, E.U., Odikamnoro, O.O., Ibiam, G.A.,
Umah, O.V. and Ariom, O.T. (2015). A survey of common gut helminth of goats slaughtered at Ankpa abattoir, Kogi state, Nigeria. Journal of Parasitology and Vector Biology, 7(5): 8993.

Ngele, K. K., Ebi, S. and Anuonye, B. C. (2018).Prevalence of intestinal helminthes in ruminants slaughtered at Abakaliki abattoir, Ebonyi State, Nigeria. Journal of Animal Science and Veterinary Medicine, 3:58-64.

Okaiyeto, S.O., Tekdek, L.B., Sackey, A.K.B. and Ajanusi, O.J. (2008). A survey of gastrointestinal parasites of nomadic sheep in eight Local Government Area of Northern Nigeria. Research Journal of Animal Sciences, 2(\$): 92-94.

Ola-Fadunsin,S.D. and Ibitoye, E.B. (2017). A retrospective evaluation of parasitic conditions and their associated risk factors in sheep and goats in Osun state, Nigeria. Sokoto Journal of Veterinary Sciences, 15(3): 20-29.

Paul, B.T., Biu, A.A., Gadzama, M.A., Ali, M., Mana, H.P. and Jairus, Y. (2016). Point prevalence and intensity of gastrointestinal parasite ova/oocyst and its association with Body Condition Score (BCS) of sheep and goats in Maiduguri, Nigeria. Journal of Advances in Parasitology, 3(3): 81-88.

Raza, A.M., Iqbal, Z., Jabbar, A. and Yaseen, M. (2007). Point prevalence of gastrointestinal helminthiasis in ruminants in Southern Punjab, Pakistan. Journal of. Helminthology, $81: 323-328$.

Raza, M.A., Younas, M. and Schlecht, E. (2014). Prevalence of gastrointestinal helminths in pastoral sheep and goat flocks in the Cholistan desert of Pakistan. The Journal of Animal \& Plant Sciences, 24:127-134.

Regassa, F., Sori, T., Dhuguma, R. and Kiros, Y. (2006). Epidemiology of gastrointestinal parasites of ruminants in Western Oromia, Ethiopia. International Journal of Applied Research in Veterinary Medicine, 4(1):51-57.

Sangma, A., Begum, N., Roy, B.C. and Gani, M.O. (2012). Prevalence of helminth parasites in sheep (Ovis aries) in Tangail district, Bangladesh. Journal of the Bangladesh Agricultural University, 10: 235-244. 